\section{The pulmonary vasculature: Achilles heel of the Fontan circulation}

The Authors' reply:

We thank Yalta and colleagues ${ }^{1}$ for their comments concerning our article reporting the relation between pulmonary artery size and functional capacity in patients with a Fontan circulation, recently published in this Journal. ${ }^{2}$ The emerging paradigm in Fontan physiology considers the pulmonary vasculature a key determinant of cardiac output. ${ }^{3}$ In the absence of obstructions in the cavopulmonary connection, both proximal pulmonary arteries and pulmonary vascular bed, in the absence of a subpulmonary pump, may represent a bottleneck limiting transpulmonary flow, and thus preload of the single ventricle and ultimately cardiac output.

In normal physiology, pulmonary vascular resistance is predominantly determined by the pulmonary vascular bed, whereas pulsatile load formed by the proximal elastic conduit arteries is minimal. However, in the Fontan circulation, the proximal elastic pulmonary arteries may significantly contribute to the total pulmonary resistance due to hypoplasia as a consequence of reduced flow conditions and abnormal growth, both prenatally and postnatally, but also because of the development of increased impedance under abnormal chronic nonpulsatile low-pressure flow from the initiation of the Fontan circulation with the instalment of the Glenn-anastomose. Finally, pulmonary artery distortions due to surgical interventions may constitute extra resistances within the pulmonary vasculature.

The single ventricle undergoes a transition from overloading to underloading (relative to ventricular size for body surface area) between initial palliation and the completion of the Fontan circulation. After Fontan completion, it is difficult to normalise preload for the 'oversized' single ventricle due to the chronic abnormal pulmonary flow conditions. Potential options to correct this reduced preload include increasing pulmonary blood flow by aortopulmonary connections, either natural or surgical, or bypassing the pulmonary circulation by means of a fenestration. Also, decreasing the impedance and resistance of the pulmonary circulation as well as increasing ventricular suction by improving lusitropy by pharmacological interventions has been suggested. ${ }^{3}$

Yalta and colleagues correctly bring up that subclinical systemic ventricular dysfunction may play a role in a reduced clinical functional status in patients with a Fontan circulation. Adequate diastolic ventricular function is crucial for a well-functioning Fontan circulation by means of maintaining low ventricular filling pressures (to increase transpulmonary gradient), but can decline over time due to chronically reduced preload which may lead to a vicious circle of deterioration of diastolic function. Presumptive evidence both through histology and clinical imaging has emerged that myocardial fibrosis associated with chronic low preload, and thus too low diastolic stretch of myocytes, contributes to this late diastolic dysfunction. Systolic ventricular dysfunction, although this may occur in patients with a Fontan circulation, is not a characteristic feature of the failing Fontan.

Yalta $e t$ al suggest that ventricular volume overload due to aortopulmonary collaterals may lead to systolic ventricular dysfunction. Although they are correct that such collateral flow could conceivably lead to ventricular overload, but since single ventricles are usually larger than normal systemic ventricles, this seems only likely when this flow is excessively large. Ample and ongoing debate exists whether aortopulmonary collaterals in the Fontan circulation will have beneficial or unfavourable effects.

In our cohort, we found Nakata index to correlate positively with cardiac index $(\mathrm{r}=0.418, \mathrm{p}=0.009)$, end-diastolic volume $(r=0.413, p=0.010)$ and stroke volume $(\mathrm{r}=0.399, \mathrm{p}=0.013)$. This supports the association between pulmonary artery size, ventricular loading and ventricular efficiency. This is in line with the current paradigm that considers the pulmonary vasculature a key factor determining ventricular preload, and thus in the longer term, ventricular diastolic function and functional capacity.

In conclusion, the pulmonary vasculature is of paramount importance for a well-functioning Fontan circulation. Treatment strategies should be aimed at optimising and balancing initial pulmonary flow and growth, starting already before instalment of the Fontan circulation. In addition, the potential positive effects of (partial) pulsatile pulmonary flow (natively or mechanically) should be (re-)considered. During follow-up, proximal pulmonary artery flowlimiting lesions should be monitored and intervened on. Molecular mechanisms involved in peripheral pulmonary vascular remodelling should be studied to identify new pharmaceutical treatment targets.

\section{Floris-Jan S Ridderbos $\odot{ }^{1}$ Tjark Ebels, ${ }^{2,3}$ Rolf M F Berger ${ }^{1}$}

${ }^{1}$ Center for Congenital Heart Diseases, Department of Paediatric Cardiology, Beatrix Children's Hospital,
University Medical Center Groningen, Groningen, The Netherlands

${ }^{2}$ Center for Congenital Heart Diseases, Department of Cardiothoracic Surgery, University Medical Center Groningen, Groningen, The Netherlands

${ }^{3}$ Department of Cardiothoracic Surgery, University

Medical Center Amsterdam, Amsterdam, The

Netherlands

Correspondence to Mr Floris-Jan S Ridderbos, Center for Congenital Heart Diseases, Department of Paediatric Cardiology, Beatrix Children's Hospital, University Medical Center Groningen, Groningen 9700 RB, The Netherlands; f.j.s.ridderbos@umcg.nl

Twitter Tjark Ebels @tjarkebels

Contributors FR drafted the manuscript. Revision: all authors. The manuscript has been read and approved by all authors for submission.

Competing interests The University Medical Center Groningen contracts with Actelion and Lilly for consultancy activities of RMFB, outside the submitted work.

Patient consent for publication Not required.

Provenance and peer review Not commissioned; internally peer reviewed.

\section{(2) OPEN ACCESS}

Open access This is an open access article distributed in accordance with the Creative Commons Attribution Non Commercial (CC BY-NC 4.0) license, which permits others to distribute, remix, adapt, build upon this work non-commercially, and license their derivative works on different terms, provided the original work is properly cited, appropriate credit is given, any changes made indicated, and the use is non-commercial. See: http://creativecommons.org/ licenses/by-nc/4.01.

(C) Author(s) (or their employer(s)) 2019. Re-use permitted under CC BY-NC. No commercial re-use. See rights and permissions. Published by BMJ.

\section{Check for updates}

To cite Ridderbos F-JS, Ebels T, Berger RMF. Heart 2019;105:1921.

Published Online First 11 November 2019

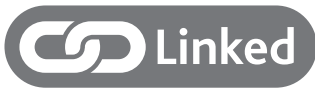

- http://dx.doi.org/10.1136/heartjnl-2019-316001

Heart 2019;105:1921.

doi:10.1136/heartjnl-2019-316136

ORCID iD

Floris-Jan S Ridderbos http://orcid.org/0000-00015101-219X

\section{REFERENCES}

1 Yalta K, Palabiyik O, Yetkin E, et al. Low pulmonary artery size might be associated with subclinical systemic ventricular dysfunction in the Fontan circulation. Heart 2019;105.

2 Ridderbos FS, Bonenkamp BE, Meyer SL, et al. Pulmonary artery size is associated with functional clinical status in the Fontan circulation. Heart 2019. doi:10.1136/ heartjnl-2019-314972. [Epub ahead of print: 06 Sep 2019].

3 Gewillig M, Brown SC. The Fontan circulation after 45 years: update in physiology. Heart 2016;102:1081-6. 